\title{
IAMJ
}

INTERNATIONAL

AYURVEDIC

MEDICAL JOURNAL

Review Article

ISSN: 2320-5091

Impact Factor: 6.719

\section{MARMA THERAPY: A NEW APPROACH OF AYURVEDA IN POST-COVID-19 STRESS MANAGEMENT}

\author{
$\underline{\text { Shailesh Singh }}^{1}, \underline{\text { D. K. Sharma }}{ }^{2}, \underline{\text { J. K. Sharma }}^{3}, \underline{\text { Purushottam Das Sharma }}^{4}$
}

${ }^{1}$ P.G. Scholar, P.G. Department of Rachana Sharir, M.M.M. GOVT. Ayurved College, Udaipur, Rajasthan, India ${ }^{2}$ Assistant Professor, P.G. Department of Rachana Sharir, M.M.M. GOVT. Ayurved College, Udaipur, Rajasthan, India

${ }^{3}$ Prof., HOD, P.G. Department of Rachana Sharir, M.M.M. GOVT. Ayurved College, Udaipur, Rajasthan, India

${ }^{4}$ Associate Professor, Department of Rachana Sharir, M.M.M. Govt. Ayurved College, Udaipur, Rajasthan, India

\section{Corresponding Author: dreamscometrue66301@gmail.com}

\section{https://doi.org/10.46607/iamj1909092021}

(Published Online: September 2021)

Open Access

(C) International Ayurvedic Medical Journal, India 2021

Article Received: 04/08//2021 - Peer Reviewed: 23/08/2021 - Accepted for Publication: 24/08/2021

Check for updates

\section{ABSTRACT}

Introduction: Ayurveda is an ancient science of medicine and surgery, here many of the treatment procedures are described for combat diseases, i.e., Ksharkarma (procedure with the help of base), Agnikarma (procedure with the help of fire), Siravedhan (procedure with the help of puncturing blood vessels), Panchkarma (purification procedure) etc. In this science Marma (vital point) therapy is like a blessing to a human being. It is a stimulation therapy of specific points. Now these days, stress arises as a major problem in COVID-19 recovered patients. It is very common to all age groups. Major causes are lack of proper classes of students, unemployment, lack of social interaction due to isolation and health status anxiety during COVID-19 infection. It arises during and post COVID-19 but especially in the post period of infection. In stress, Marma therapy has an important role because it helps to maintain the equilibrium of the body by working on body humour. Objective: To provide costless, chemical-free and effective treatment for post-COVID-19 patients. Data Source: Relevant various Ayurvedic literature, Samhitas (classical books), modern literature, journals, magazines and online available materials. considered. Review Method: Relevant various data source materials were considered for this. Result: stress will be relieved because this therapy acts directly on hormones secretion which is responsible for relieving stress. Conclusion: By this therapy, a patient gets relief without any expenses and the most important is that without using hormonal treatment. 
Marma therapy in stress can relieve stress by maintaining calmness in the brain, it helps to maintain the brain's proper functioning. By this therapy, not only the stress but stress-related other complications can be treated.

Keywords: Marma therapy, COVID-19, post-covid-19, stress.

\section{INTRODUCTION}

Marmas are the vital areas of the body. This word "Marma" comes from the Sanskrit origin word 'mri' meaning death. The Sanskrit phrase, 'Marayate Iti Marmani', also means death or serious damage to the body after got excessive pressure to the point of their situation. Hence these areas are called "Marma". By definition, a Marma point is a junction on the body where two or more types of tissue like muscles, veins, ligaments, bones or joints meet. Acharya Sushruta describes 107 Marma points in the body. Major Marma points correspond to seven Chakras (energy centres) of the body, while minor points radiate out along the trunk and extremities. The mind is considered the $108^{\text {th }}$ Marma. Each Marma has its name based on its anatomical position. The human body needs Shodhana (revitalisation) to perform its function normally and efficiently. A professional Marma therapist isolates Marma points and tones them by increasing blood flow to the affected part of the neuromuscular junction by pressing these points. They also aim to tone the surrounding muscles. ${ }^{[1]}$

COVID-19 pandemic arose as the destroyer of the human community since 2019, in India it came in 2020 and from that time it is continuously increasing in the form of $1^{\text {st }}$ and $2^{\text {nd }}$ wave now India is leading to the $3^{\text {rd }}$ wave of it.

COVID-19 is a contagious disease. It is caused by severe acute respiratory syndrome coronavirus 2 (SARS-CoV-2). The very first case was identified in Wuhan, China in December 2019.

Although most people with COVID-19 get better within weeks of illness, some people experience postCOVID-19 situations. Post-COVID-19 conditions are a wide range of new, returning, or ongoing health problems people can experience more than four weeks after first being infected with the virus that causes COVID-19. Even people who did not have symptoms when they were infected can have post-COVID-19 conditions. These conditions can have different types and combinations of health problems for different lengths of time. Symptoms that can last weeks or months after first being infected with the virus that causes COVID-19 or can appear weeks after infection. ${ }^{[2]}$ This is known as long COVID-19. It can happen to anyone who has had COVID-19, even if the illness was mild, or they had no symptoms. People with long COVID-19 report experiencing different combinations of the symptoms; in which stress-related symptoms are: ${ }^{[3]}$

- Difficulty in thinking or concentrating (sometimes referred to as "brain fog")

- Depression or anxiety

- Stress

Stress is a state of physical or mental tension which tend to disturb an existent equilibrium. In the stress, sense organ produces excessive stimuli which go to the brain and lead to increased activity of the psychic centre of the brain. It leads to psychosomatic disorder, heart diseases, anxiety, migraine, insomnia, diabetes, and hypertension etc. Depression or anxiety, Difficulty in thinking or concentrating are the very common post-COVID-19 effects on recovered patients. Excessive thinking about the life or death or complication and severe effects of COVID-19 during their isolation period makes the patient stressed. Stress can't be diagnosed easily because every person has some tension about their work.

AIM and OBJECTIVE: To provide costless, chemical-free and effective treatment for post-COVID-19 patients.

\section{MATERIALS \& METHODS:}

MATERIALS - Relevant various Ayurvedic literature, Samhitas, modern literature, journals, magazines and online available materials considered.

METHODS - Marma therapy is a stimulation therapy in which stimulation is given with the help of fingers 
on a fixed area. The area must be accurate, otherwise either this therapy doesn't work or produces side effects. For the Marma therapy in these conditions some Marma points should be stimulated; AdhipatiSeemant-Sthapani-Talhriday-Kurcha-Kurchashira.

15-18 times pressure should be given in one sitting on each Marma, same as the rhythm of our respiration. Pressure should be mild to moderate, depending upon the tolerance capacity of a person.

\section{LITERATURE REVIEW-}

ADHIPATI MARMA: "Mastakabhyantaroparishthat sirasandhisannipato romavarto adhipatih, tatrapi sadya eva" ${ }^{[4]}$ It is a Sandhi (joint) Marma half finger in width, located at the topmost portion of the body as a chieftain. Inside the forehead and superiorly is located the conjointment of Sira sandhi (junction of blood vessels) which is representing outwardly by a spiral of hairs on the top of the skull where injury leads to death. ${ }^{[4]}$ Under this region superior sagittal sinus, straight sinus terminates and the right, left transverse sinus begins; this area is known as Torcular Herophili (confluence of sinuses). Indirectly it is related to the hypothalamus.

SEEMANT MARMA: "Panch sandhyah shirasi vibhaktah seemanta naam tatronmadabhayacittanashairmaranam"

Seemant Marma (sutures) is Sandhi Marma which is five in number and located at the skull where sutures are present (frontal, occipital, parietal bones meet). Beneath the sutures, the Dural venous sinuses are situated.

STHAPANI MARMA: "Bhruvo madhye sthapani naam tatrotkshepavat" ${ }^{\prime[4]}$

It is a Sira Marma (blood vessels), located between the eyebrows measuring half finger width. Just beneath this area under the skull bone, there is glabella and venous reservoir of the brain, the superior sagittal and cavernous venous sinuses, so immediate removal of the foreign body will cause excessive bleeding.

TALHRIDAY: (Hand) "Madhyamanggulim anupurvena madhye padatalasya talahrudayam nama tatra rujabhirmaranam" [5]

Here Acharya mentioned Paad (extremity) it's the common term for upper and lower extremities. It is located in the centre of the palm (the centre point of an imaginary vertical line drawn between the middle finger and the centre of the wrist). Here the following structures are situated: Palmar aponeurosis, Palmaris longus, Adductor pollicis, Palmar branch of the median nerve, superficial and deep palmar arch, Flexor digitorum superficialis, Dorsal interosseous.

KURCHA: (Hand) "Kshiprasyoparishtad ubhayatah kurco nama, tatra padasya bhramanavepane bhavatah" ${ }^{[5]}$ It is Snayu Marma, located on the thenar eminence, measuring four finger widths. Here the following structures are situated: Superior palmar branch of the radial artery, Branch of the median nerve to the muscles of the thenar eminence

KURCHASHIR: (hand) "Gulphasandheradha ubhayatah kurcashirah, tatra rujashophau" [5] Here, Acharya mentioned Gulpha (ankle/ wrist), it's the common term for ankle and the wrist joint. It is Snayu Marma, located on the wrist, measuring one finger width. Here the following structures are situated: Flexor retinaculum, median nerve.

\section{DISCUSSION}

\section{STRESS}

Mental strain leads to excessive liberation of acetylcholine, catecholamine like neurohumors from the brain, which causes many systemic diseases.

Persistent stress leads to the increased sympatho-adrenomedullary activity of the limbic and hypothalamic regions of the brain. Through this process, the catecholamine level becomes high which then produces general vasoconstriction and hypertension.

Adrenaline and noradrenaline are secreted from the adrenal medulla in small quantities even during rest. During stress conditions, due to sympathoadrenal discharge, a large quantity of catecholamines is secreted. Adrenalin increases the activity of the brain. Its secretion increases during 'fight or flight reactions' after exposure to stress. It enhances the cortical arousal and other facilitatory functions of the central nervous system. ${ }^{[6]}$

\section{- MODE OF ACTION \\ $\checkmark$ On ADHIPATI MARM:}


When rhythmic pressure is exerted on this Marma, the beneath structures gets rhythmic pressure resulted in the release of eyestrain during stress because the occipital lobe of the cerebrum is responsible for visual centre functioning. And on the other hand, the torcular herophili is the part of the brain from where Marma stimulation directly affects the brain's venous drainage system and helps to maintain normal blood flow in the brain, which calms down the body during stress. This Marma point is the chief point of the head, works directly on the whole brain and the brain is the primary organ for body functioning.

\section{$\checkmark$ On SEEMANT MARMA:}

This Marma resembles the sutures of the brain. Dural venous sinuses are present beneath these sutures. These venous sinuses work to drain deoxygenated blood from the brain. Due to the Marma therapy on this Marma helps to maintain the rhythmic flow of C.S.F. and gives stimulation to the hypothalamus-pituitary gland for generating negative feedback to release cortisol. Its stimulation provides calmness to the mind and also abolish diseases related to the brain.

\section{$\checkmark$ On STHAPANI MARMA:}

Marma therapy on this Marma indirectly stimulates the pineal gland which is responsible to maintain the biological clock. It helps to relieve stress generated insomnia.

Overall, these three Marma are directly or indirectly gives stimulation to the cerebrum, hypothalamus, limbic system and spinal cord.

When we give pressure (stress) on a point, it stimulates the hypothalamus. The stimulated hypothalamus regulates the secretion of cortisol by controlling the ACTH secretion through corticotropin-releasing factor (CRF). CRF reaches the anterior pituitary through the hypothalami-hypophyseal portal vessels. CRF stimulates the corticotropes of the anterior pituitary and causes the synthesis and release of ACTH. CRF secretion is induced by several factors such as emotion, stress, trauma and circadian rhythm. CRF, in turn, causes the release of ACTH, which induces glucocorticoid secretion

$\checkmark$ On TALHRIDAY, KURCHA, KURCHASHIR MARMA: When rhythmic pressure exerts on the
Median nerve, Superior and deep palmar arch, palmar aponeurosis, radial and ulnar artery; it generates rhythmic impulses in these structures.

\section{On Median nerve -}

These impulse from median nerve goes to the brachial plexus and then in the grey matter of spinal cord, now impulses reach to the brain and the brain works to maintain equilibrium by inhibiting the release of norepinephrine to reduce stress on the median nerve.

\section{On Radial and Ulnar artery-}

When rhythmic pressure exerts on these vessels then the blood flow speed reduces and gets the normal blood pressure with a normal speed of flow. Because the Marma therapy has a gap of $0.8 \mathrm{sec}$ in two pressures, which is the same as the cardiac cycle. So, it helps tos prevents HTN and cardiac problems.

\section{Physiology in Marma therapy:}

Exposure to any type of stress, either physical or mental, increases the secretion of adrenocorticotropic hormone (ACTH), which in turn increases glucocorticoid secretion. The increase in glucocorticoid level is very essential for survival during stress conditions, as it offers high resistance to the body against stress. ${ }^{[6]}$

\section{CONCLUSION}

In post-COVID-19, patient overthinks about their health status resulted in an increased level of stress generating hormone, and persistent thinking does not give negative feedback to the brain to down the level of catecholamines. Anti-depressants or sleeping pills are the only treatment for these conditions in modern science. These medicines alter the mental state for a fixed time. To relieve stress, the patient takes these medications continuously which harms the body's other organs and progresses to new pathology in the body.

Marma therapy in stress can relieve stress by doing permanent calmness in the brain, it helps to maintain the brain's proper functioning. By this therapy, not only the stress but stress-related other complications can be treated. By this therapy, a patient gets relief without any expenses and the most important is that without using hormonal treatment. 


\section{REFERENCES}

1. nhp.gov.in/Marma_therapy_mt/ Back to cited text no. 01

2. Wikipedia.org/wiki/COVID-19-19 Back to cited text no. 02

3. https://www.cdc.gov/coronavirus/2019-ncov/longterm-effects.html_Back to cited text no. 03

4. Sushruta Samhita, Sharir Sthana, PratayekaMarmanirdeshashariram, 19(27) Available from http://niimh.nic.in/ebooks/esushruta. [Last accessed on 2021 July 22] Back to cited text no. 04

5. Sushruta Samhita, Sharir Sthana, PratayekaMarmanirdeshashariram, 16(24) Available from http://niimh.nic.in/ebooks/esushruta. [Last accessed on 2021 July 22] Back to cited text no. 05

6. K Sembulingam Prema Sembulingam, Essential of medical physiology, $6^{\text {th }}$ edition, Jaypee Brothers Medical Publishers (P) Ltd. Back to cited text no. 05

7. B.D. Chaurasia, Human Anatomy, $8^{\text {th }}$ edition, CBS Publishers \& Distributors Pvt Ltd. Back to cited text no. 06

\section{Source of Support: Nil Conflict of Interest: None Declared}

How to cite this URL: Shailesh Singh et al: Marma Therapy: A New Approach Of Ayurveda In Post-Covid-19 Stress Management. International Ayurvedic Medical Journal \{online\} 2021 \{cited September 2021\} Available from: http://www.iamj.in/posts/images/upload/2057_2061.pdf 